\title{
Correlation between frontal sinus dimensions and cephalometric indices: A cross-sectional study
}

\author{
Azita Tehranchi ${ }^{1}$, Saeed Reza Motamedian ${ }^{2}$, Sara Saedi $^{3}$, Sattar Kabiri $^{2}$, Shireen Shidfar $^{4}$
}

Correspondence: Dr. Saeed Reza Motamedian

Email: sr.motamedian@yahoo.com

\begin{abstract}
'Preventive Dentistry Research Center, Research Institute of Dental Sciences, Dental School, Shahid Beheshti University of Medical Sciences, Tehran, Iran, ${ }^{2}$ Department of Orthodontics, Dental School, Shahid Beheshti University of Medical Sciences, Tehran, Iran, ${ }^{3}$ Dental Research Center, Research institute of Dental Sciences, Dental School, Shahid Beheshti University of Medical Sciences, Tehran, Iran,

${ }^{4}$ Department of Periodontics, School of Dentistry,

Shahed University, Tehran, Iran
\end{abstract}

\section{ABSTRACT}

Objective: Growth prediction plays a significant role in accurate diagnosis and treatment planning of orthodontics patients. It was hypothesized that the unique pattern of pneumatization of the frontal sinus as a component of craniofacial structure would influence the skeletal growth pattern and may be used as a growth predictor. Materials and Methods: A total of 144 subjects (78 females and 66 males) with a mean age of $19.26 \pm 4.66$ years were included in this retrospective study. Posterior-anterior and lateral cephalograms (LCs) were used to measure the frontal sinus dimensions. The skeletal growth pattern and relations of craniofacial structures were analyzed on LC using variables for sagittal and vertical analyses. Correlation between the frontal sinus dimensions and cephalometric indices was assessed by the Pearson's correlation coefficient. Results: The SN-FH and SNA angles had significant associations with frontal sinus dimensions in all enrolled subjects $(P<0.05)$. In males, the SN-FH, sum of posterior angles, Pal-SN, and Jarabak index were significantly associated with the size of frontal sinus $(P<0.05)$. In females, the associations of SN-FH and gonial angles with frontal sinus dimensions were significant $(P<0.05)$. Conclusion: The results show that larger size of frontal sinus was associated with reduced inclination of the anterior cranial base, increased anterior facial height (in males), and increased gonial angle (in females) in the study population.

Key words: Analysis, anatomic variation, cephalometry, frontal sinus, radiography

\section{INTRODUCTION}

Growth prediction is defined as the estimation of alterations in speed and direction of future growth. ${ }^{[1]}$ The growth patterns of the mandible, maxilla, and other craniofacial structures should be taken into consideration as essential components to determine the time of occurrence, duration, and prognosis of malocclusions. Growth prediction

\begin{tabular}{|l|l|}
\hline \multicolumn{2}{|c|}{ Access this article online } \\
\hline Quick Response Code: \\
\hline
\end{tabular}

can help clinicians in more accurate diagnosis and treatment planning. ${ }^{[2]}$

Development of craniofacial bones takes place in relation to one another and is influenced by various factors. The frontal sinus, one of the paranasal sinuses located in the skull, is formed following pneumatization

This is an open access article distributed under the terms of the Creative Commons Attribution-NonCommercial-ShareAlike 3.0 License, which allows others to remix, tweak, and build upon the work non-commercially, as long as the author is credited and the new creations are licensed under the identical terms.

For reprints contact: reprints@medknow.com

How to cite this article: Tehranchi A, Motamedian SR, Saedi S, Kabiri S, Shidfar S. Correlation between frontal sinus dimensions and cephalometric indices: A cross-sectional study. Eur J Dent 2017;11:64-70.

DOI: $10.4103 / 1305-7456.202630$ 
of the frontal bone, which is directly influenced by the interactions of the respiratory epithelium and activity of adjacent osteoclasts. ${ }^{[3,4]}$ Pneumatization may be absent in frontal bone, resulting in sinus aplasia. ${ }^{[5]}$ Since the left and right sinuses are developed independently, asymmetrical sinuses may also be found. Variations in the extent of pneumatization individualize frontal sinus morphology and diversity in shape and capacity and symmetry of the frontal sinus. ${ }^{[6]}$ The visibility of the frontal sinus on radiographs depends on the amount of pneumatization. Frontal sinus anatomy can also help in identification of the deceased by comparing pre- and post-mortem radiographs. ${ }^{[7,8]}$

Evidence shows that frontal sinus dimensions are multifactorial and related to genetic factors and weather conditions. ${ }^{[9]}$ In 1990, Blaney stated that craniofacial structures affect the morphology of the paranasal sinuses. ${ }^{[10]}$ An association between hypertrophic frontal sinus and overgrowth of the mandible exists in acromegaly (production of excessive amounts of growth hormone).$^{[11]}$ The correlation of frontal sinus anatomy and its dimensions with the mandible in patients with normal systemic conditions has been previously evaluated..$^{[5,12-15]}$ Rossouw et al. ${ }^{[5]}$ suggested the area of frontal sinus as a predictor of mandibular growth pattern and concluded that a Class III patient with a larger frontal sinus would more likely need an orthognathic surgery besides orthodontic appliances in the future. They reported that larger frontal sinuses were associated with skeletal Class III malocclusion, longer condyles, and wider symphysis ${ }^{[5]}$ Another study on adults with skeletal Class I, II and III relations measured the area of frontal sinus on their lateral cephalograms (LCs) and indicated that large frontal sinuses were associated with large mandibles irrespective of their positional relationship; however, there was evidence that Class III skeletal malocclusions were more likely associated with larger frontal sinus areas. ${ }^{[12]}$ Others have investigated the relationship between the development of the frontal sinus and the person's height and concluded that frontal sinus can serve as an indicator for assessment of developmental maturity. ${ }^{[13-15]}$

Frontal sinus can be evaluated in the sagittal plane using lateral cephalometry and in the coronal plane using posterior-anterior (PA) cephalometry, which are routinely ordered for orthodontics patients. This study was designed to assess the possible associations between the frontal sinus dimensions and craniofacial indices both sagittal and vertical, using pretreatment LC and $\mathrm{PA}$ radiographs in a group of the Iranian population.

\section{MATERIALS AND METHODS}

\section{Study population}

This retrospective study was approved by the Research Institute of Dental Sciences, Shahid Beheshti University of Medical Sciences, Tehran, Iran. It was performed on patients presenting to the Department of Orthodontics, Dental School, Shahid Beheshti University of Medical Sciences from 2011 to 2013. The included patients were $\geq 12$ years old and had true scale LC and PA radiographs. All these radiographs were taken using a Cranex D X-ray unit (Soredex, Helsinki, Finland) with exposure settings of $66-70 \mathrm{kVp}, 10 \mathrm{~mA}$, and $14.2 \mathrm{~s}$, with patient in centric occlusion and natural head position.

The exclusion criteria were as follows:

- Patients with no records of their age or gender

- Patients with signs of infection or sinus pathology based on radiographs

- Congenital syndromes involving craniofacial bones, palatal clefts, hemifacial microsomia, or hypertrophy

- History of trauma to the nasomaxillary complex

- History of orthognathic surgery

- Poor quality of radiographs.

\section{Measuring sinus dimensions}

Sinus dimensions were measured on PA radiographs and LC of patients before orthodontic treatment by Dolphin Imaging Software (Dolphin Imaging, Chatsworth, CA, USA) [Figure 1a and b]. Briefly, sinus borders were marked excluding the crista galli by an experienced orthodontist. Extension of the superior orbital rim was considered as the lower limit of

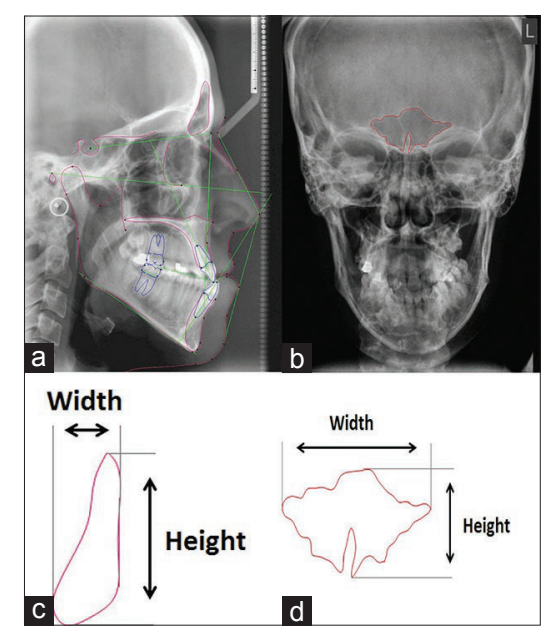

Figure 1: A sample case of frontal sinus measurement and cephalometric analysis. (a) Landmarks on lateral cephalogram. (b) Frontal sinus traced on posterior-anterior cephalogram. (c) Measurement of sinus dimensions on the sagittal plane. (d) Measurement of sinus dimensions on the coronal plane 
sinus, in cases in whom the inferior sinus border was not detectable. ${ }^{[16,17]}$ Measurements of the maximum height, width, and area of the frontal sinuses were made by AutoCAD 2007 software (Autodesk Inc., San Rafael, CA, USA) with $2.5 \%$ error in both sagittal and frontal planes by two examiners [Figure $1 \mathrm{c}$ and $\mathrm{d}] .^{[18]}$ The mean values of measurements made by the two examiners were reported for each patient. Intraclass correlation coefficient was measured to assess the interexaminer reliability.

\section{Cephalometric analysis}

Anatomical landmarks were identified through Dolphin software, and their accuracy was ensured by an orthodontist [Figure 1a]. Fifteen cephalometric variables representing maxillofacial growth pattern in both vertical and anterior-posterior dimensions were calculated [Tables 1 and 2]. ${ }^{[19]}$

\section{Statistical analysis}

Descriptive values (mean and standard deviation) were reported for each parameter. Normal distribution of data was confirmed by Kolmogorov-Smirnov test $(P>0.05)$. Student's $t$-test for independent samples was used to compare sinus dimensions between males and females. The relationship between sinus dimensions and cephalometric indices was assessed by the Pearson's correlation coefficient. To control for the effect of age and gender on this relationship, a linear

\begin{tabular}{|c|c|}
\hline Landmark & Definition \\
\hline Sella (S) & Midpoint of sella \\
\hline Nasion $(\mathrm{N})$ & The most anterior point of the frontonasal suture \\
\hline Porion (Po) & Uppermost point of the external auditory meatus \\
\hline Orbitale (Or) & Lowermost point of the bony orbit \\
\hline Articular & $\begin{array}{l}\text { Intersection of the images of the } \\
\text { posterior margin of the ramus and the } \\
\text { outer margin of the cranial base }\end{array}$ \\
\hline Gonion (Go) & $\begin{array}{l}\text { Intersection of the lines tangent to } \\
\text { the posterior border of the ramus and } \\
\text { the lower border of the mandible }\end{array}$ \\
\hline $\begin{array}{l}\text { Anterior nasal } \\
\text { spine (ANS) }\end{array}$ & $\begin{array}{l}\text { The most anterior point of the tip } \\
\text { of the anterior nasal spine }\end{array}$ \\
\hline $\begin{array}{l}\text { Posterior nasal } \\
\text { spine (PNS) }\end{array}$ & $\begin{array}{l}\text { Intersection of the continuation of the } \\
\text { anterior wall of the pterygomaxillary } \\
\text { fissure and the nasal floor }\end{array}$ \\
\hline Menton (Me) & $\begin{array}{l}\text { The most inferior point of the } \\
\text { outline of the symphysis }\end{array}$ \\
\hline Gnathion (Gn) & The most anterior inferior point on the bony chin \\
\hline Pogonion (Pog) & The most anterior point of the symphysis \\
\hline A-point & $\begin{array}{l}\text { The deepest point on the outer contour } \\
\text { of the maxillary alveolar process }\end{array}$ \\
\hline B-point & $\begin{array}{l}\text { The deepest point on the outer contour of the } \\
\text { mandibular alveolar process }\end{array}$ \\
\hline
\end{tabular}

regression model was applied. Statistical analysis was performed using SPSS version 21 software (SPSS Inc., IL, USA) at a significance level of 0.05 .

\section{RESULTS}

A total of 144 subjects were enrolled; of which, 78 were female and 66 were male. The mean age of patients was $19.26 \pm 4.66$ years (range: $13-31$ years). The intraclass correlation coefficient for interexaminer reliability was 0.83 , which is considered excellent.

\section{Frontal sinus dimensions}

Table 3 reports the average dimensions of the frontal sinus. The average dimensions of the frontal sinus in both sagittal and frontal planes in males were greater than those in females. However, according to the independent $t$-test, this difference was only significant in the transverse dimension in the frontal plane $(P=0.032)$.

\section{Cephalometric indices}

The mean values of cephalometric indices are presented in Table 4. The average measurements on LC were not significantly different between males and

\begin{tabular}{|c|c|}
\hline Index & Definition \\
\hline $\mathrm{SN}-\mathrm{FH}$ & $\begin{array}{l}\text { Angle between anterior cranial base (SN) } \\
\text { and Frankfurt plane (Po-Or) }\end{array}$ \\
\hline Saddle & $\begin{array}{l}\text { Angle between anterior cranial } \\
\text { base (SN) and sella to articular }\end{array}$ \\
\hline Articular & Angle between sella to articular and articular to gonial \\
\hline Gonial & $\begin{array}{l}\text { Angle between articular to gonial and } \\
\text { mandibular plane (Go-Me) }\end{array}$ \\
\hline $\begin{array}{l}\text { Sum of } \\
\text { posterior }\end{array}$ & Sum of saddle, articular and gonial angles \\
\hline $\begin{array}{l}\text { Facial } \\
\text { angle }\end{array}$ & $\begin{array}{l}\text { Angle between nasion to pogonion } \\
\text { and Frankfurt plane (Po-Or) }\end{array}$ \\
\hline Occ-SN & $\begin{array}{l}\text { Occlusal plane angle in relation to } \\
\text { anterior cranial base }(\mathrm{SN})\end{array}$ \\
\hline Pal-SN & $\begin{array}{l}\text { Palatal plane (ANS-PNS) angle in relation } \\
\text { to anterior cranial base (SN) }\end{array}$ \\
\hline Man-SN & $\begin{array}{l}\text { Mandibular plane (Go-Me) angle in } \\
\text { relation to anterior cranial base (SN) }\end{array}$ \\
\hline SNA & Anteroposterior position of A-point \\
\hline SNB & Anteroposterior position of B-point \\
\hline ANB & $\begin{array}{l}\text { Anteroposterior relationship between A-point } \\
\text { and B-point with respect to nasion }\end{array}$ \\
\hline Wits & $\begin{array}{l}\text { Distance between a line constructed from } \\
\text { Point A perpendicular to the occlusal } \\
\text { plane and a line constructed from Point B } \\
\text { perpendicular to the occlusal plane }\end{array}$ \\
\hline Y-axis & $\begin{array}{l}\text { Angle between } Y \text {-axis (S-Gn) and } \\
\text { anterior cranial base (SN) }\end{array}$ \\
\hline $\begin{array}{l}\text { Jarabak } \\
\text { index }\end{array}$ & $\begin{array}{l}\text { Posterior facial height (S-Go) to anterior facial } \\
\text { height }(\mathrm{N}-\mathrm{Me}) \text { ratio }(\%)\end{array}$ \\
\hline
\end{tabular}


females except for the ANB angle, which was $0.56^{\circ}$ $\pm 4.93^{\circ}$ in males and $3.32^{\circ} \pm 3.96^{\circ}$ in females $(P=0.048)$.

Correlation between the frontal sinus size and maxillofacial dimensions

Assessment of the relationship between the dimensions of the frontal sinus and cephalometric indices revealed

\begin{tabular}{|c|c|c|c|c|}
\hline & Minimum & Maximum & Mean & SD \\
\hline \multicolumn{5}{|c|}{$\begin{array}{l}\text { Lateral } \\
\text { cephalometry }\end{array}$} \\
\hline Width & 0.43 & 2.00 & 1.1530 & 0.39104 \\
\hline Height & 1.18 & 3.36 & 2.3182 & 0.58847 \\
\hline Area & 83.00 & 193.00 & 129.3864 & 23.86222 \\
\hline \multicolumn{5}{|c|}{$\begin{array}{l}\text { Posteroanterior } \\
\text { cephalometry }\end{array}$} \\
\hline Width & 0.47 & 7.41 & 5.1757 & 1.44574 \\
\hline Height & 0.72 & 4.34 & 2.8282 & 0.74522 \\
\hline Area & 88.00 & 191.00 & 123.6136 & 18.71104 \\
\hline
\end{tabular}

\begin{tabular}{|c|c|c|c|c|}
\hline & Minimum & Maximum & Mean & SD \\
\hline $\mathrm{SN}-\mathrm{FH}$ & 1 & 18 & 7.30 & 3.764 \\
\hline Saddle & 109 & 137 & 123.30 & 7.473 \\
\hline Articular & 135 & 162 & 144.20 & 5.987 \\
\hline Gonial & 114 & 142 & 129.91 & 6.994 \\
\hline Sum of posterior & 383 & 412 & 399.22 & 6.293 \\
\hline Facial angle & 72 & 95 & 86.55 & 4.791 \\
\hline Occ-SN & 3 & 31 & 17.95 & 5.754 \\
\hline Pal-SN & 2 & 17 & 8.57 & 4.411 \\
\hline Man-SN & 21 & 54 & 37.25 & 7.980 \\
\hline SNA & 69 & 91 & 79.86 & 4.921 \\
\hline SNB & 71 & 87 & 77.55 & 4.123 \\
\hline ANB & -7 & 11 & 2.32 & 4.487 \\
\hline Wits & -14 & 6 & -2.66 & 5.374 \\
\hline Y-axis & 60 & 80 & 69.34 & 4.870 \\
\hline Jarabak index & 0.3630 & 0.8521 & 0.659179 & 0.0851843 \\
\hline
\end{tabular}

SD: Standard deviation

\begin{tabular}{|c|c|c|c|}
\hline Index & Sinus dimension & $R$ & $P$ \\
\hline \multirow[t]{4}{*}{$\mathrm{SN}-\mathrm{FH}$} & Sinus width (lateral view) & -0.483 & 0.001 \\
\hline & Sinus height (lateral view) & -0.479 & 0.001 \\
\hline & Sinus width (frontal view) & -0.492 & 0.001 \\
\hline & Sinus height (frontal view) & -0.426 & 0.004 \\
\hline SNA & Sinus height (frontal view) & -0.323 & 0.032 \\
\hline
\end{tabular}

a significant association of SN-FH and SNA angles with frontal sinus size [Table 5]. In males, the SN-FH, sum of posterior angles, Pal-SN, and Jarabak index had significant associations with the size of the frontal sinus [Table 6]; while in females, only SN-FH and gonial angles were significantly correlated with frontal sinus dimensions [Table 7].

A regression model was applied adjusted for age and gender. The results showed a significant correlation between sinus dimensions and SN-FH, sum of posterior angles, and Jarabak index [Table 8]. Neither age nor gender affected the correlation between frontal sinus dimensions and cephalometric indices.

\section{DISCUSSION}

Growth of the maxilla and nasal cavity is closely related to the development of paranasal sinuses and all these structures ultimately determine the final morphology of the face. ${ }^{[20]}$ Studies conducted on twins have shown that the shape of sinuses is mainly determined by genetics; ${ }^{[16,21]}$ however, environmental factors, trauma, allergies, acquired conditions, nutrition, and drug use can also affect the development of sinuses. ${ }^{[22]}$ Genotype and growth of maxillofacial structures are two major factors that affect frontal sinus dimensions. ${ }^{[21]}$ Considering the multifactorial size of the frontal sinus, the current study assessed the relationship between the cephalometric indices and frontal sinus dimensions in a group of Iranian patients. The results revealed good correlations between some cephalometric indices and frontal sinus size.

In the current study, PA radiographs and LC were used to assess the dimensions of the frontal sinus. LCs provide an optimal view to examine the PA walls of the frontal sinus, and the sinus area is visible on PA radiographs. ${ }^{[2,24]}$ The previous studies have shown that physiological changes in the size of the frontal sinus after the age of 12 are minimal; ${ }^{[21,23,24]}$ thus, only patients over 12 years of age were enrolled in this study. A noteworthy result was that the dimensions of the frontal sinus were larger in males compared to females; however, this difference was not statistically significant. Similarly, previous studies reported larger frontal sinus in men compared to women, ${ }^{[2,26]}$ and this difference was not significant in some of them. ${ }^{[16,23,27]}$

In total population of the study, a significant inverse correlation was found between SN-FH angle and the dimensions of the frontal sinus, especially its height in sagittal and frontal planes. The increase in the size 


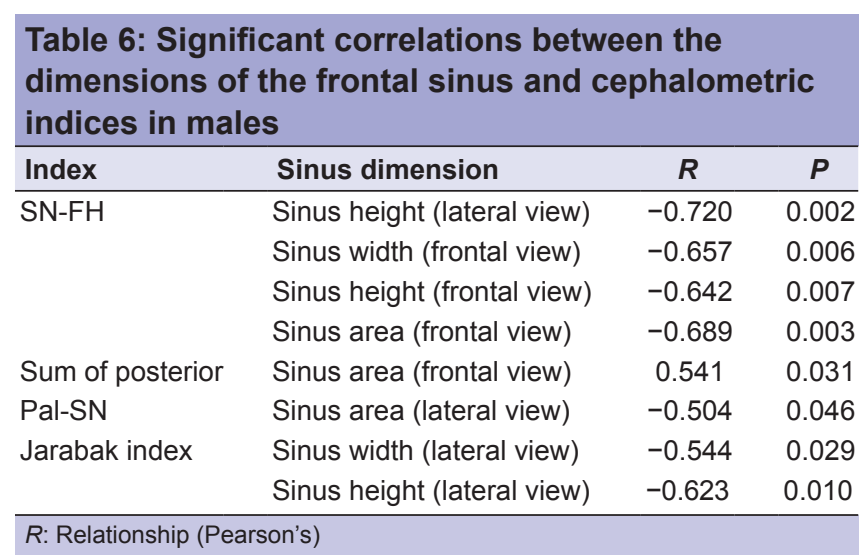

\begin{tabular}{|c|c|c|c|}
\hline Index & Sinus dimension & $R$ & $P$ \\
\hline \multirow[t]{3}{*}{$\mathrm{SN}-\mathrm{FH}$} & Sinus width (lateral view) & -0.549 & 0.002 \\
\hline & Sinus height (lateral view) & -0.378 & 0.048 \\
\hline & Sinus width (frontal view) & -0.470 & 0.012 \\
\hline Gonial & Sinus area (lateral view) & 0.425 & 0.024 \\
\hline
\end{tabular}

\begin{tabular}{|c|c|c|c|c|}
\hline Index & $\begin{array}{l}\text { Sinus } \\
\text { dimension }\end{array}$ & Parameter & $B$ & $P$ \\
\hline \multirow[t]{12}{*}{$\mathrm{SN}-\mathrm{FH}$} & \multirow{3}{*}{$\begin{array}{l}\text { Sinus width } \\
\text { (lateral view) }\end{array}$} & Gender & 0.467 & 0.657 \\
\hline & & Age & 0.096 & 0.372 \\
\hline & & $\begin{array}{l}\text { Sinus width } \\
\text { (lateral view) }\end{array}$ & -3.360 & 0.016 \\
\hline & \multirow{3}{*}{$\begin{array}{l}\text { Sinus height } \\
\text { (lateral view) }\end{array}$} & Gender & 0.589 & 0.566 \\
\hline & & Age & 0.090 & 0.390 \\
\hline & & $\begin{array}{l}\text { Sinus height } \\
\text { (lateral view) }\end{array}$ & -2.419 & 0.003 \\
\hline & \multirow{3}{*}{$\begin{array}{l}\text { Sinus width } \\
\text { (frontal view) }\end{array}$} & Gender & 1.425 & 0.168 \\
\hline & & Age & 0.181 & 0.079 \\
\hline & & $\begin{array}{l}\text { Sinus width } \\
\text { (frontal view) }\end{array}$ & -1.275 & $<0.001$ \\
\hline & \multirow{3}{*}{$\begin{array}{l}\text { Sinus height } \\
\text { (frontal view) }\end{array}$} & Gender & 0.813 & 0.436 \\
\hline & & Age & 0.118 & 0.260 \\
\hline & & $\begin{array}{l}\text { Sinus height } \\
\text { (frontal view) }\end{array}$ & -1.859 & 0.004 \\
\hline \multirow{3}{*}{$\begin{array}{l}\text { Sum of } \\
\text { posterior }\end{array}$} & \multirow{3}{*}{$\begin{array}{l}\text { Sinus area } \\
\text { (frontal view) }\end{array}$} & Gender & -1.761 & 0.402 \\
\hline & & Age & -0.149 & 0.549 \\
\hline & & $\begin{array}{l}\text { Sinus area } \\
\text { (frontal view) }\end{array}$ & 0.189 & 0.006 \\
\hline \multirow{3}{*}{$\begin{array}{l}\text { Jarabak } \\
\text { index }\end{array}$} & \multirow{3}{*}{$\begin{array}{l}\text { Sinus width } \\
\text { (lateral } \\
\text { view) }\end{array}$} & Gender & 0.014 & 0.610 \\
\hline & & Age & 0.001 & 0.731 \\
\hline & & $\begin{array}{l}\text { Sinus width } \\
\text { (lateral view) }\end{array}$ & 0.112 & 0.011 \\
\hline
\end{tabular}

of frontal sinus resulted in the lower inclination of the anterior cranial base from the horizontal plane. It could be justified that the nasion point, which is the anterior landmark of the SN plane, is influenced by the dimensions of the frontal sinus. An inverse correlation between the SN-FH angle and sinus dimensions was also observed when analyzing females and males separately. This provides strong evidence for the influence of frontal sinus on the inclination of anterior cranial base.

Only one correlation was found between the anterior-posterior growth of skeletal structures and dimensions of the frontal sinus. This correlation was found between the SNA and height of the sinus in the frontal plane and might indicate a tendency for maxillary retrognathism in individuals with increased height of frontal sinus. On the other hand, the ANB and Wits indices showed no significant relations with the dimensions of the frontal sinus. Therefore, according to the results presented here, the skeletal relation of the maxilla and mandible in the sagittal plane was not influenced by the dimensions of the frontal sinus. The results did not show any correlation between the size of the frontal sinus and Angle classification in the studied population.

In both females and males, associations were found between the frontal sinus size and vertical cephalometric indices. After controlling for the confounding factors of age and gender, a significant correlation was found between frontal sinus size and SN-FH, sum of posterior angles and Jarabak index. In males, the sum of posterior angles showed a positive correlation with the sinus area. In cases with larger sinus area, a larger anterior facial height can be expected. The negative correlation between the Jarabak index and sinus dimensions in the lateral view supports this finding. A poor inverse correlation was also observed in males between the Pal-SN angle and the sinus area. This finding could again be justified by the influence of frontal sinus on the location of nasion and the inclination of cranial base as well as clockwise rotation of the maxilla, which could result in increased anterior facial height. Similar to males, a correlation was found in females between the sinus area and the gonial angle, which supports increased steepness of the mandible.

Some controversies exist when comparing our findings with those of previous studies. ${ }^{[5,12]}$ As previously 
described, there were no significant associations between the position of the maxilla and mandible in the sagittal plane with frontal sinus dimensions, other than the weak tendency for maxillary retrognathism in the present study, while in other studies, larger frontal sinus was correlated with excessive mandibular growth and Class III skeletal malocclusion. ${ }^{[5,12]}$ Rossouw et al. ${ }^{[5]}$ assessed the association between the area of the frontal sinus and excessive mandibular overgrowth by comparing fifty skeletal Class I and 53 skeletal Class III patients. The only radiograph used in their study was the LC, and the area of the sinus was measured using a digitizer connected to a microcomputer. They claimed that sinus area can serve as a predictor of abnormal mandibular growth according to the measurements of mandibular length, symphysis width, porion location, ramus position, and condylar axis. Among the anteroposterior angles, only ANB was used for the analysis. ANB was the common variable measured in both studies; however, a negative correlation between ANB and sinus area was reported by Rossouw et al. ${ }^{[5]}$ concluding that larger sinus areas are associated with skeletal Class III malocclusion. No correlations were reported in their study between the frontal sinus size and the facial angle, indicating that a large frontal sinus may be present in vertical growers. While, there was a significant association between increased vertical dimension and sinus size in the current study. Prashar et al. ${ }^{[12]}$ also demonstrated that larger sinus areas were strongly associated with larger mandibles, with a tendency for Class III skeletal malocclusion. However, smaller sinus areas did not indicate a Class II skeletal malocclusion.

The inherent limitation of conventional twodimensional radiographs for measuring the volume of complex three-dimensional anatomical structures is considered as a limitation of the present study. A computed tomography scan of the frontal sinus would enable more accurate analysis of sinus dimensions; however, the aim of this study was to identify expected associations between the frontal sinus anatomy and craniofacial structures on LC and PA radiographs routinely ordered by orthodontists. Furthermore, patient malpositioning or slight movements when taking radiographs could cause inaccuracies in the measurement of frontal sinus size and cephalometric indices. In this study, radiographs with any sign of distortion were excluded.

To generalize the results to the clinical setting, it should be noted that prediction of growth of craniofacial structures in the diagnosis phase can help achieve stable and favorable outcomes in orthodontic patients, and clinicians should use all the tools available for this purpose. ${ }^{[5]}$ Dimensions of the frontal sinus, which are visible on routine orthodontic radiographs, may be used as an indicator to assess the vertical growth. However, the current study was a cross-sectional study and growth prediction could not be concluded. The results showed an association between frontal sinus size and some cephalometric indices in adult patients. Based on these results, the authors could only suggest that in young adults, in whom the frontal sinus has reached its maximum size (while the vertical growth continues), larger frontal sinus might be associated with future vertical growth. To confirm this, longitudinal studies are required.

\section{CONCLUSION}

Considering the limitations of the present study, greater dimensions of the frontal sinus might be associated with decreased inclination of the anterior cranial base (SN). There was also a correlation between frontal sinus dimensions and increased anterior facial height (sum of posterior angles, Pal-SN, and Jarabak index) in males and increased gonial angle in females.

\section{Financial support and sponsorship \\ Nil.}

\section{Conflicts of interest}

There are no conflicts of interest.

\section{REFERENCES}

1. Turchetta BJ, Fishman LS, Subtelny JD. Facial growth prediction: A comparison of methodologies. Am J Orthod Dentofacial Orthop 2007;132:439-49.

2. Oueis H, Ono Y, Takagi Y. Prediction of mandibular growth in Japanese children age 4 to 9 years. Pediatr Dent 2002;24:264-8.

3. Aki T, Nanda RS, Currier GF, Nanda SK. Assessment of symphysis morphology as a predictor of the direction of mandibular growth. Am J Orthod Dentofacial Orthop 1994;106:60-9.

4. Collin-Osdoby P, Rothe L, Anderson F, Nelson M, Maloney W, Osdoby P. Receptor activator of NF-kappa B and osteoprotegerin expression by human microvascular endothelial cells, regulation by inflammatory cytokines, and role in human osteoclastogenesis. J Biol Chem 2001;276:20659-72.

5. Rossouw PE, Lombard CJ, Harris AM. The frontal sinus and mandibular growth prediction. Am J Orthod Dentofacial Orthop 1991;100:542-6.

6. Singer CP, Mamandras AH, Hunter WS. The depth of the mandibular antegonial notch as an indicator of mandibular growth potential. Am J Orthod Dentofacial Orthop 1987;91:117-24.

7. Lambrechts AH, Harris AM, Rossouw PE, Stander I. Dimensional differences in the craniofacial morphologies of groups with deep and shallow mandibular antegonial notching. Angle Orthod 1996;66:265-72.

8. Huggare J. The first cervical vertebra as an indicator of mandibular growth. Eur J Orthod 1989;11:10-6.

9. Chaiyasate S, Baron I, Clement P. Analysis of paranasal sinus 
Tehranchi, et al.: Frontal sinus and facial dimensions correlation

development and anatomical variations: A CT genetic study in twins. Clin Otolaryngol 2007;32:93-7.

10. Blaney SP. Why paranasal sinuses? J Laryngol Otol 1990;104:690-3.

11. Chanson P, Salenave S. Acromegaly. Orphanet J Rare Dis 2008;3:17.

12. Prashar A, Sharma VP, Singh G, Singh GP, Sharma N, Singh H. A cephalometric study of frontal sinus and its relation with craniofacial patterns. Indian J Dent Sci 2012;4:4-8.

13. Ruf S, Pancherz H. Development of the frontal sinus in relation to somatic and skeletal maturity. A cephalometric roentgenographic study at puberty. Eur J Orthod 1996;18:491-7.

14. Gagliardi A, Winning T, Kaidonis J, Hughes T, Townsend GC. Association of frontal sinus development with somatic and skeletal maturation in Aboriginal Australians: A longitudinal study. Homo 2004;55:39-52.

15. Guevara YV, Watanabe N, Yamaki M, Saito I. The frontal sinus enlargement as an indicator of growth maturity in Class III patients - A pilot study. Int J Med Sci Public Health 2013;2:451-5.

16. Yoshino M, Miyasaka S, Sato H, Seta S. Classification system of frontal sinus patterns by radiography. Its application to identification of unknown skeletal remains. Forensic Sci Int 1987;34:289-99.

17. Hanson CL, Owsley DW. Frontal sinus size in Eskimo populations. Am J Phys Anthropol 1980;53:251-5.

18. Santana L, Guadagnin R, Reis CL, Cavalcante J, Júnior E, Neves RD. Area evaluation using image processing tools: An applied study to pressure ulcer monitoring. Pattern Recognit Image Anal 2010;20:220-4

19. Rakosi T, Jonas I, Graber TM. Orthodontic Diagnosis. Foreword by Moyers RE. [Translation by Reule-Giles Dental Service]. Stuttgart, New York: G. Thieme Verlag, Thieme Medical Publishers; 1993. p. 179-205.

20. Sadler TW, Langman J. Langman's Essential Medical Embryology. Vol. 1. Philadelphia: Lippincott Williams \& Wilkins; 2004. p. 176.

21. Szilvássy J. Development of the frontal sinuses. Anthropol Anz 1981;39:138-49.

22. Kjær I, Pallisgaard C, Brock-Jacobsen MT. Frontal sinus dimensions can differ significantly between individuals within a monozygotic twin pair, indicating environmental influence on sinus sizes. Acta Otolaryngol 2012;132:988-94.

23. Schuller A. Note on the identification of skulls by X-ray pictures of the frontal sinuses. Med J Aust 1943;1:554-6.

24. Dolan KD. Paranasal sinus radiology, part IA: Introduction and the frontal sinuses. Head Neck Surg 1982;4:301-11.

25. Harris AM, Wood RE, Nortjé CJ, Thomas CJ. The frontal sinus: Forensic fingerprint? A pilot study. J Forensic Odontostomatol 1987;5:9-15.

26. Pondé JM, Metzger P, Amaral G, Machado M, Prandini M. Anatomic variations of the frontal sinus. Minim Invasive Neurosurg 2003;46:29-32.

27. Tehranchi A, Saedi S, Motamedian SR, Rohani K. Radiographic evaluation of frontal sinus dimensions and anatomic variations. $\mathrm{Br} J$ Med Med Res 2015;8:454-62. 